\title{
Development of graphite structure with heat treatment in a carbon sheet derived from cellulose nanofibrils of plant origin
}

Yutaka Kaburagi $^{\text {a),*}}$, Miu Ohoyama ${ }^{\text {a) }}$, Emi Shindo ${ }^{\text {b) }}$, Akira Yoshida ${ }^{\text {b) }}$, Norio Iwashita $^{\text {c) }}$, Noriko Yoshizawa ${ }^{\text {c) }}$ and Masaya Kodama ${ }^{\text {c) }}$

\begin{abstract}
Commercially available pure cellulose paste of plant origin composed of nanofibrils was dispersed in ethanol or distilled water, and sheets made of the nanofibrils were prepared by filtration. The sheets were carbonized and then heat-treated at temperatures between 2400 and $3200{ }^{\circ} \mathrm{C}$ at atmospheric pressure, and the original paste was also carbonized and heat-treated at $3100{ }^{\circ} \mathrm{C}$. The diameter of the cellulose nanofibrils was found to be $30-300 \mathrm{~nm}$ in the sheets, while no fibrous texture was observed in the original paste. Structural order of the carbonized sheets improved with increasing heat treatment temperature, and was especially remarkable for the sheet derived from nanofibrils dispersed in ethanol, though turbostratic components were observed even for the sheet heat-treated at $3200{ }^{\circ} \mathrm{C}$. On the other hand, the $3100{ }^{\circ} \mathrm{C}$-treated paste exhibited a typical turbostratic structure. The development of graphite structure in the carbon sheets is probably attributed to surface graphitization, the same as the graphitization of the carbonized sheets prepared from bacteria cellulose nanofibers by heat treatment at high temperatures reported previously. The structural development of the present heat-treated sheets was less than that of the heattreated sheets prepared from bacteria cellulose nanofibers. The result could be attributed to the thicker diameters and lower crystallinity of the present precursor nanofibrils compared to those of the bacteria cellulose nanofibers.
\end{abstract}

KEYWORDS : Cellulose nanofibril, Plant pulp, Surface graphitization, Graphitic carbon nanofiber, Non-graphitizing carbon

\section{Introduction}

Cellulose-based carbon materials are essentially known to be one of nongraphitizing carbons ${ }^{1)}$ and exhibit multiphase graphitization ${ }^{2)}$. In the case of cellulose films, the surfaces of carbonized films i.e., the skins of 100-200 nm thick, were graphitized by simple heat treatment at high temperatures ${ }^{3)}$, and also the skin regions of about 70-80 nm thick of cellulose-based carbon fibers were graphitized by simple heat treatment at high temperatures ${ }^{4)}$. A mechanical stress was applied to the skin regions during the formation processes of the fibers and films. The stress enhanced the preferred orientation of cellulose molecules of the skin regions. After carbonization, so called basal structural units probably aligned along each surface of the fibers and films, so that the surfaces seemed to be graphitized by simple heat treatment at high temperatures.
On the other hand, Kim et al. reported that a $500{ }^{\circ} \mathrm{C}$-treated sample of freeze-dried bacteria cellulose was graphitized by heat treatment at $2000{ }^{\circ} \mathrm{C}$ for 5 min in vacuo ${ }^{5)}$. Bacteria cellulose is known to be composed of crystalline cellulose nanofibrils ${ }^{6}$. From the X-ray diffraction (XRD) measurements for the bacteria cellulose-derived carbons heattreated at $2000{ }^{\circ} \mathrm{C}$, however, the average crystallite size along $c$-axis $L_{\mathrm{c}}$ was obtained to be $3.7 \mathrm{~nm}$ and no separation of 100 and 101 diffraction peaks were observed ${ }^{5}$. We found that sheets prepared from the bacteria cellulose nanofibers with $30-60 \mathrm{~nm}$ in diameter dispersed in ethanol or distilled water were graphitized by simple heat treatment at high temperatures up to $3200{ }^{\circ} \mathrm{C}$ after carbonization ${ }^{7), 8}$. The sheets prepared in ethanol and carbonized were graphitized well in comparison with those in water because the separation of cellulose nanofibers dispersed in ethanol was better. For example, the interlayer spacing $d_{002}$ and $L_{\mathrm{c}}$ were $0.3378 \mathrm{~nm}$ and $22 \mathrm{~nm}$, respectively, for

* Corresponding Author, E-mail: ykabura@tcu.ac.jp

(Received January 10, 2013, Accepted April 3, 2013)

a) Faculty of Engineering, Tokyo City University: 1-28-1 Tamazutsumi, Setagaya-ku, Tokyo 158-8557, Japan

b) Instrumental Analysis Center, Tokyo City University: 1-28-1 Tamazutsumi, Setagaya-ku, Tokyo 158-8557, Japan

c) National Institute of Advanced Industrial Science and Technology. AIST: Tsukuba 305-8568, Japan

http://dx.doi.org/10.7209/tanso.2013.187 
the sample dispersed in ethanol and heat-treated at $3200{ }^{\circ} \mathrm{C}$ for $5 \mathrm{~min}$. The development of graphite structure was thought to be attributed to the graphitization on the surface of nongraphitizing carbon, and the surface graphitization seemed to have a obvious effect on the insides of the carbon nanofibers because of very thin diameters ${ }^{7), 8)}$. However, the structural improvement with heat treatment for the carbon sheets was less remarkable in comparison with that for typical graphitizing carbons. The limited graphitization behavior of the heat-treated sheets was attributed to their heterogeneous structure.

Recently, entangled cellulose nanofibrous network prepared from purified natural cellulose powder, which was derived from plant pulp, was investigated as a low cost precursor of carbon nanofibers ${ }^{9), 10)}$. The cellulose nanofibrous network consisting of nanofibrils with $5-10 \mathrm{~nm}$ in diameter was made by a waterjet treatment of the plant pulp and freeze-dried technique. After a heat treatment at $2500{ }^{\circ} \mathrm{C}$, some limited area of the fibrous region of the network exhibited development of stacking structure consisting of 10-20 carbon layers being extended to $50 \mathrm{~nm}$ at longest and roughly in parallel with other nanofibrils, though the structural parameters of the heat-treated network, such as the mean interlayer spacing and mean crystallite sizes, were not examined ${ }^{10)}$

Commercially available cellulose paste consisting of elemental nanofibrils, similar to the cellulose nanofibrous network as mentioned above, but with around $10-100 \mathrm{~nm}$ in diameters, has been obtained from plant pulp by smashing it to submicroscopic fragments mechanically ${ }^{11), 12)}$. It was found that the $3000{ }^{\circ} \mathrm{C}$-treated sample of the carbon nanofiber aggregate prepared from the cellulose paste was not graphitized $^{12)}$. The result seems to be due to the aggregation of the carbon nanofibers. The separation of cellulose nanofibrils is important factor for the development of graphite structure ${ }^{7), 8}$. The cellulose nanofibrils are very cohesive because of nanometer sizes. To prevent the cohesion of the cellulose nanofibrils, the nanofibrils have to be dispersed in ethanol or distilled water since cellulose, $\left(\mathrm{C}_{6} \mathrm{H}_{10} \mathrm{O}_{5}\right)_{n}$, has hydroxyl radicals ${ }^{7), 8)}$.

There has been no systematic experimental investigation of the structural development of carbon nanofibers obtained from cellulose nanofibrils of plant origin with simple heat treatment up to high temperature, such as $3100{ }^{\circ} \mathrm{C}$. In addition, the cellulose nanofibrils of plant origin are easy to obtain because of commercially available ones, and they are very cheap in comparison with the bacteria cellulose nanofibrils, though their mean diameters are larger than those of the bacteria cellulose nanofibers. In the present study, the commercially available cellulose nanofibrils of plant origin were dispersed in ethanol or distilled water, and sheets made of the nanofibrils were prepared by filtration of the dispersed nanofibrils, and the structural development of the carbonized sheets with heat treatment was examined systematically.

\section{Experimental}

The cellulose nanofibril paste used in this study was a commercial product with trade name "Cellish FD-100G" produced by Daicel Fine Chemical Ltd. ${ }^{11)}$ The cellulose nanofibril paste was dispersed in ethanol or distilled water (hereafter Et or $\mathrm{H}_{2} \mathrm{O}$ ). Paper like sheets composed of the cellulose nanofibrils of about $1 \mathrm{~mm}$ in thickness were obtained by the same way as refs. 7 and 8 . The cellulose sheets obtained were designated by the abbreviations of cellulose (Cel) and liquid used, i.e. Cel-Et and $\mathrm{Cel}-\mathrm{H}_{2} \mathrm{O}$.

From the measurements of X-ray fluorescence, Cel-Et and Cel$\mathrm{H}_{2} \mathrm{O}$ were composed of $\mathrm{C}$ and $\mathrm{O} . \mathrm{C}_{1 \mathrm{~s}}$ and $\mathrm{O}_{1 \mathrm{~s}}$ peaks were only observed by the measurements of X-ray photoelectron spectroscope, and also Fourier transform infrared spectra show $\mathrm{OH}, \mathrm{CH}, \mathrm{CO}, \mathrm{C}-\mathrm{C}$, $\mathrm{CH}_{2}$ vibrations, corresponding to the molecular structure of cellulose.

Cel-Et and Cel- $\mathrm{H}_{2} \mathrm{O}$ were carbonized at $900{ }^{\circ} \mathrm{C}$ for $1 \mathrm{~h}$ in an $\mathrm{Ar}$ flow, and then the sheets were heat-treated at temperatures of 3000 and $3100{ }^{\circ} \mathrm{C}$ and kept for $30 \mathrm{~min}$, and at $3200^{\circ} \mathrm{C}$ for $5 \mathrm{~min}$ in a high purity Ar flow at atmospheric pressure. The carbonized Cel-Et sheets were also heat-treated at temperatures of 2400,2600 and $2800{ }^{\circ} \mathrm{C}$ and kept for $30 \mathrm{~min}$ in a high purity Ar flow at atmospheric pressure. The samples were designated by Cel-Et or Cel- $\mathrm{H}_{2} \mathrm{O}$ followed by the heat treatment temperature (HTT), such as Cel-Et-3000. To examine the effect of the dispersion of the nanofibrils in ethanol or distilled water, the original cellulose nanofibril paste, Cel-Paste, was dried in air, and the solid sample was carbonized and then heat-treated at $3100{ }^{\circ} \mathrm{C}$ and kept for $30 \mathrm{~min}$ in a high purity Ar flow (denoted hereafter as CelPaste-3100).

The texture and structure of the heat-treated sheets were investigated by observations using a scanning electron microscope (SEM) and transmission electron microscope (TEM) and by measurements of first-order Raman spectra, XRD and DC electric resistivity. The Raman spectra were measured on five different areas of each heattreated sample using an Ar ion laser of $514.5 \mathrm{~nm}$ in wavelength. The diameter of the laser beam was $1 \mu \mathrm{m}$. The ratio of the peak intensity of $\mathrm{D}$ band (a disorder-induced band) to that of $\mathrm{G}$ band (a Raman active lattice vibration band of graphite), $I_{\mathrm{D}} / I_{\mathrm{G}}$, and full width at the half maximum of the G band, G-FWHM, were determined for the heat-treated samples. To examine the crystallinity of the cellulose nanofibril precursor used in this study, the XRD measurements were carried out for the Cel-Et sheet. The XRD measurements were also performed for the sheets made of bacteria cellulose nanofibers ${ }^{5,7), 8}$ (Bact-Et) and animal cellulose nanofibers ${ }^{5)}$ (Ani-Et) for comparison, which were dispersed in ethanol and filtered. For the heat-treated sheets of Cel-Et and Cel- $\mathrm{H}_{2} \mathrm{O}$ and Cel-Paste-3100, the XRD profiles were measured separately in the regions of $20^{\circ}-35^{\circ}$ and $35^{\circ}-85^{\circ}$, and the precise measurements were carried out between $49^{\circ}-57^{\circ}$. From the XRD measurements of the heat-treated samples, the values of 
the interlayer spacing $d_{002}$ were evaluated by the same way as refs. 7 and 8. Electric resistivity along the longitudinal direction of each sheet, sheet resistivity $\rho$, was measured at room temperature in air by a conventional DC four terminal method for Cel-Et-3000, -3100 and -3200 .

\section{Results and Discussion}

\subsection{SEM}

Figure 1 shows the SEM images of the original samples and the $900{ }^{\circ} \mathrm{C}$ - and $3000{ }^{\circ} \mathrm{C}$-treated samples, i.e., Cel-Et (a) and the extended image (c), Cel-Paste (b), Cel- $\mathrm{H}_{2} \mathrm{O}$ (d), Cel-Et-900 (e), Cel$\mathrm{H}_{2} \mathrm{O}-900$ (f), Cel-Et-3000 (g) and Cel- $\mathrm{H}_{2} \mathrm{O}-3000$ (h). In both of CelEt and $\mathrm{Cel}-\mathrm{H}_{2} \mathrm{O}$, the nanofibrils were oriented along each sheet surface as shown in Figs. 1(a), (c) and (d), while no fibrous texture was observed in Cel-Paste as shown in Fig. 1(b). It can be estimated that the nanofibrils in Cel-Paste cohered each other strongly and made a thick lump. The diameters of the nanofibrils observed in Figs. 1(c) and (d) were about 30-300 nm, which were somewhat larger than the catalogue values of $10-100 \mathrm{~nm}^{11)}$. The nanofibrils also stuck together
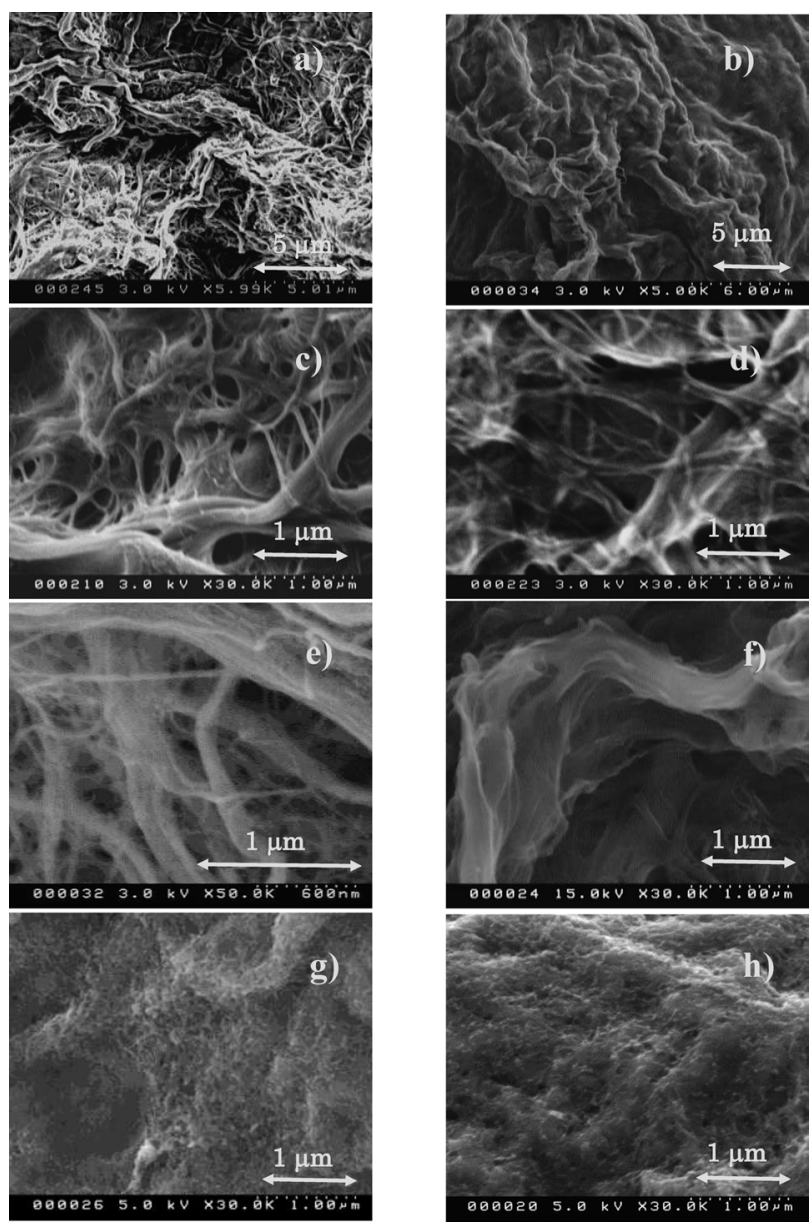

Fig. 1 SEM images of the original samples and the $900{ }^{\circ} \mathrm{C}$ - and $3000^{\circ} \mathrm{C}$-treated ones. Cel-Et (a), original cellulose nanofibril paste dried in air (b), extended image of Cel-Et (c), Cel$\mathrm{H}_{2} \mathrm{O}$ (d), Cel-Et 900 (e), Cel- $\mathrm{H}_{2} \mathrm{O}-900$ (f), Cel-Et-3000 (g) and Cel- $\mathrm{H}_{2} \mathrm{O}-3000$ (h) to some extent even in Cel-Et, but the separation of the nanofibrils in Cel-Et seems to be better than that of the nanofibrils in $\mathrm{Cel}-\mathrm{H}_{2} \mathrm{O}$, as the same trend as that of the bacteria cellulose nanofibers in their sheets $^{7,8)}$. The diameter distribution of the present nanofibrils was broader than that of the bacteria cellulose nanofibers with $30-60 \mathrm{~nm}$ in diameter ${ }^{7), 8)}$

The samples shrank after the heat treatment at $900{ }^{\circ} \mathrm{C}$ and the fibrous texture remained in Cel-Et-900, but not in Cel- $\mathrm{H}_{2} \mathrm{O}-900$, as shown in Figs. 1(e) and (f). The results indicate that the degree of separation of individual nanofibers depends on the sample treatment of cellulose nanofibers.

The samples shrank further after the high temperature heat treatments, and no individual nanofibers were observed in both of CelEt-3000 and Cel- $\mathrm{H}_{2} \mathrm{O}-3000$ as shown in Figs. 1(g) and (h). In the case of the $3100{ }^{\circ} \mathrm{C}$-treated carbon sheets derived from Bact-Et, some individual nanofibers were still observed, while the individual nanofibers were hard to observe for the $3100{ }^{\circ} \mathrm{C}$-treated sheets derived from Bact- $\mathrm{H}_{2} \mathrm{O}$ and also for Bact-NT-3100 ${ }^{8}$. Bact- $\mathrm{H}_{2} \mathrm{O}$ is a sheet composed of bacteria cellulose nanofibers dispersed in water and filtered, and Bact-NT-3100 is an original aggregate of bacteria cellulose nanofibers heat-treated at $3100{ }^{\circ} \mathrm{C}$ after carbonization. The cellulose nanofibers decomposed and were carbonized during the heat treatment up to $900{ }^{\circ} \mathrm{C}$, but the decomposition was not finished at $900{ }^{\circ} \mathrm{C}$. They further decompose during the heat treatment up to high temperatures, such as $2000^{\circ} \mathrm{C}$. In the course of the decomposition, the nanofibers tend to stick together if they touch together and entangle each other. The degree of separation of individual nanofibers depends on the sample treatment of cellulose nanofibers and also the origin of the nanofibers. The present cellulose nanofibrils are the commercially available ones which are obtained from plant pulp by smashing it to submicroscopic fragments mechanically, and the fragments entangle each other as shown in Figs. 1(a), (c) and (d). Therefore, during the decomposition and carbonization of the cellulose nanofibrils even in Cel-Et and $\mathrm{Cel}-\mathrm{H}_{2} \mathrm{O}$, the nanofibers stick together in some degree, and by the high temperature heat treatment the nanofibers seem to make an aggregate. Consequently, no individual nanofibers were found on the surfaces of Cel-Et-3000 and Cel- $\mathrm{H}_{2} \mathrm{O}-3000$ by the SEM observations. On the other hand, the bacteria cellulose nanofibers are produced by acetic acid bacteria and are crystalline cellulose with rather uniform texture, though the nanofibers also somewhat entangle each other, but the degree of separation is much better than that in the present cellulose nanofibrils ${ }^{8)}$. Therefore, some individual nanofibers were still observed for the $3100^{\circ} \mathrm{C}$-treated carbon sheets derived from Bact-Et as mentioned above.

\subsection{TEM}

By the TEM observations, a fibrous texture was observed for all heat-treated Cel-Et and Cel- $\mathrm{H}_{2} \mathrm{O}$ sheets as shown in Figs. 2(a), (b) and (c) for Cel-Et-3100 as examples. A graphitic area on Cel-Et-3100 

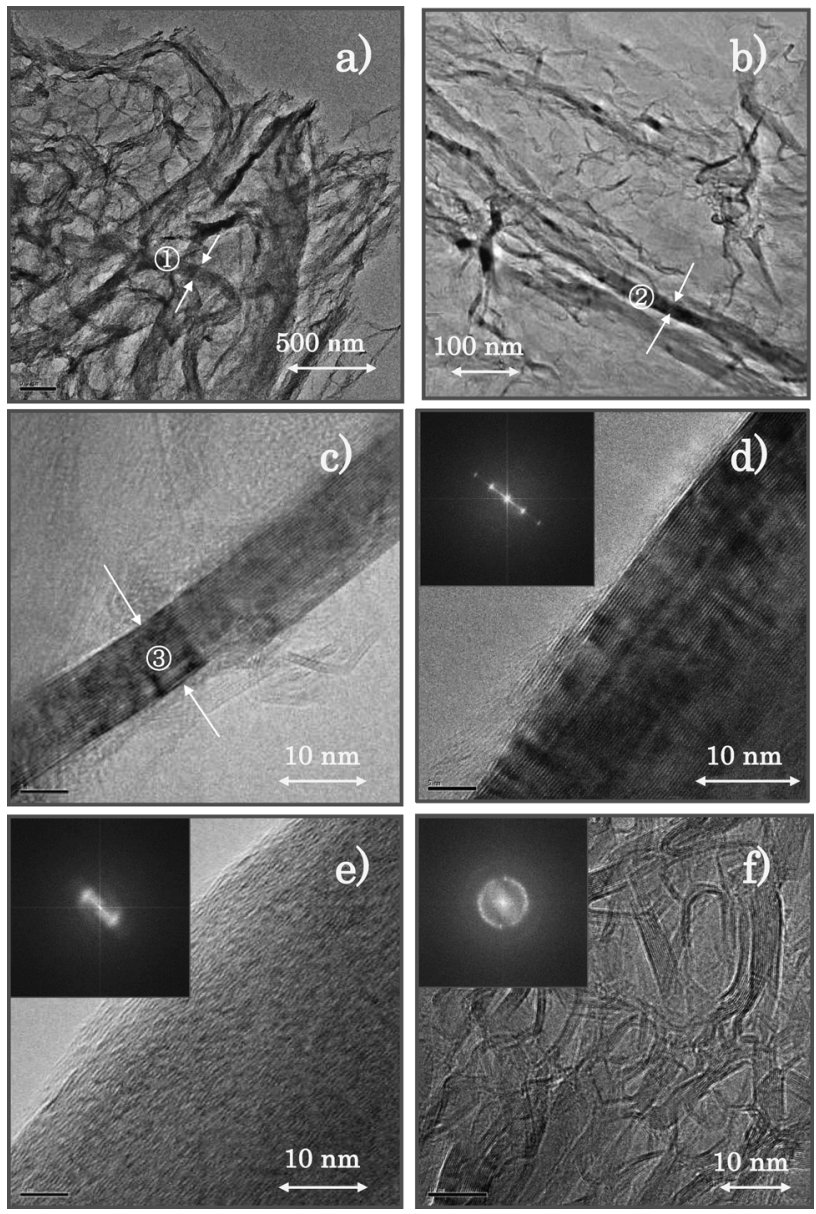

Fig. 2 TEM images of Cel-Et-3100. (a) and (b) are the bright field images, (c) and (d) are the 002 lattice fringes of graphitic parts, and (e) and (f) are those of turbostratic parts. The insets in (d), (e) and (f) are the FFT images of the 002 lattice fringes in (d), (e) and (f). Each of (1), (2) and (3) indicates a diameter of each carbon nanofiber in (a), (b) and (c), respectively.

is shown in Figs. 2(c) and (d). Stacked hexagonal carbon layers, running parallel each other, extended along the axis of the carbonized nanofibril. Each of (1), (2) and (3) indicates a diameter of each carbon nanofiber in and Figs. 2(a), (b) and (c), respectively. The diameters of the $3100{ }^{\circ} \mathrm{C}$-treated carbon nanofibers observed are distributed widely, being about $10-300 \mathrm{~nm}$, which approximately correspond to those of the original cellulose nanofibrils of about 30-300 nm estimated from the SEM observations. For example, the diameter (1) in Fig. 2(a) is about $100 \mathrm{~nm}$, (2) in Fig. 2(b) is about $20 \mathrm{~nm}$ and (3) in Fig. 2(c) is about $10 \mathrm{~nm}$. On the other hand, the fibrous texture was not observed by the SEM observations as shown in Fig. 1(g) and (h) for the $3000{ }^{\circ} \mathrm{C}$-treated carbon nanofibers as mentioned above. Even though the carbon nanofibers entangle each other, stick together and make an aggregate, the fibrous texture should remain, but the texture may not be obvious on the sample surface as observed using SEM. The difference between the SEM and TEM results seems to be attributed to the difference between the images formed by transmission

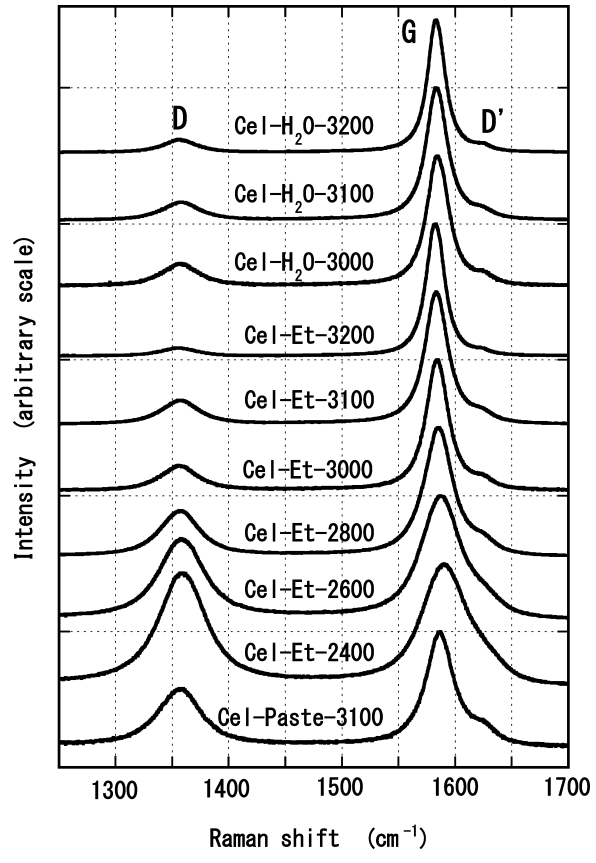

Fig. 3 Raman spectra for heat-treated samples of Cel-Et and Cel$\mathrm{H}_{2} \mathrm{O}$ and for Cel-Paste-3100.

electrons through specimens and those by the secondary electrons on the specimen surfaces.

The heat-treated sheets were found to be composed of graphitic and turbostratic components as shown in Figs. 2(c)-(f) as examples. The insets in Figs. 2(d)-(f) are the two dimensional fast Fourier transform (FFT) images of the 002 lattice fringes in these figures. Different types of the turbostratic areas are shown in Figs. 2(e) and (f). In Fig. 2(e), carbon layers with small sizes tended to parallel along the axis of the carbonized nanofibril. Thin entangled turbostratic ribbons were observed in Fig. 2(f). The regions exhibiting turbostratic structures seem to correspond to the inhomogeneous nanofibrils, inside of thick nanofibrils and disordered parts in the cellulose sheets.

\subsection{Raman spectra}

Raman spectra measured on the five different areas of the surfaces of each heat-treated sample differed from one another. The irradiated area of the Ar laser beam with $1 \mu \mathrm{m}$ in diameter is large enough compared with the nanotexture of the carbonized nanofibrils, and the Raman spectrum relates not only to the surface structure, but also the orientation of carbon layers. Therefore, the Raman data were somewhat scattered by area to area. The Raman spectra measured on the five different areas were averaged, and the mean Raman spectrum for each heat-treated sheet of Cel-Et, Cel- $\mathrm{H}_{2} \mathrm{O}$ and Cel-Paste-3100 are shown in Fig. 3. The D and $\mathrm{D}^{\prime}$ bands in addition to the $\mathrm{G}$ band were observed for all heat-treated samples measured. The intensity of the D band for the heat-treated sheet of Cel-Et and also that of Cel- $\mathrm{H}_{2} \mathrm{O}$ decreased with the increase of HTT. The results indicate that both carbon sheets prepared from Cel-Et and $\mathrm{Cel}-\mathrm{H}_{2} \mathrm{O}$ show improvement in structural order with HTT. On the other hand, the D 
band of Cel-Paste-3100 was intense though heat-treated at $3100^{\circ} \mathrm{C}$, indicating non-graphitizing nature. Organic materials exhibiting solid phase carbonization, such as cellulose and furan resin, are basically known to be the precursors of nongraphitizing carbon, and the result for Cel-Paste-3100 is a typical case for the nongraphitizing carbon heat-treated at high temperatures ${ }^{1,2)}$. The development of graphite structure on Cel-Et-3100 and Cel- $\mathrm{H}_{2} \mathrm{O}-3100$ seems to be attributed to graphitization behavior on the surface of nongraphitizing carbon, and the surface graphitization is effective against the carbon nanofibers with very thin diameters, i.e., with high surface aria ${ }^{4), 7), 8)}$.

The values of G-FWHM and $I_{\mathrm{D}} / I_{\mathrm{G}}$ were plotted as a function of HTT in Figs. 4(a) and (b), respectively. The values of G-FWHM and $I_{\mathrm{D}} / I_{\mathrm{G}}$ for the heat-treated Bact-Et and $\mathrm{Bact}-\mathrm{H}_{2} \mathrm{O}$ and for BactNT-3100 are also plotted as a function of HTT in the figures for comparison $^{8)}$. G-FWHM and $I_{\mathrm{D}} / I_{\mathrm{G}}$ decreased with increasing HTT for the heat-treated Cel-Et and $\mathrm{Cel}-\mathrm{H}_{2} \mathrm{O}$ sheets, indicating structural improvement with increasing HTT. The G-FWHM and $I_{\mathrm{D}} / I_{\mathrm{G}}$
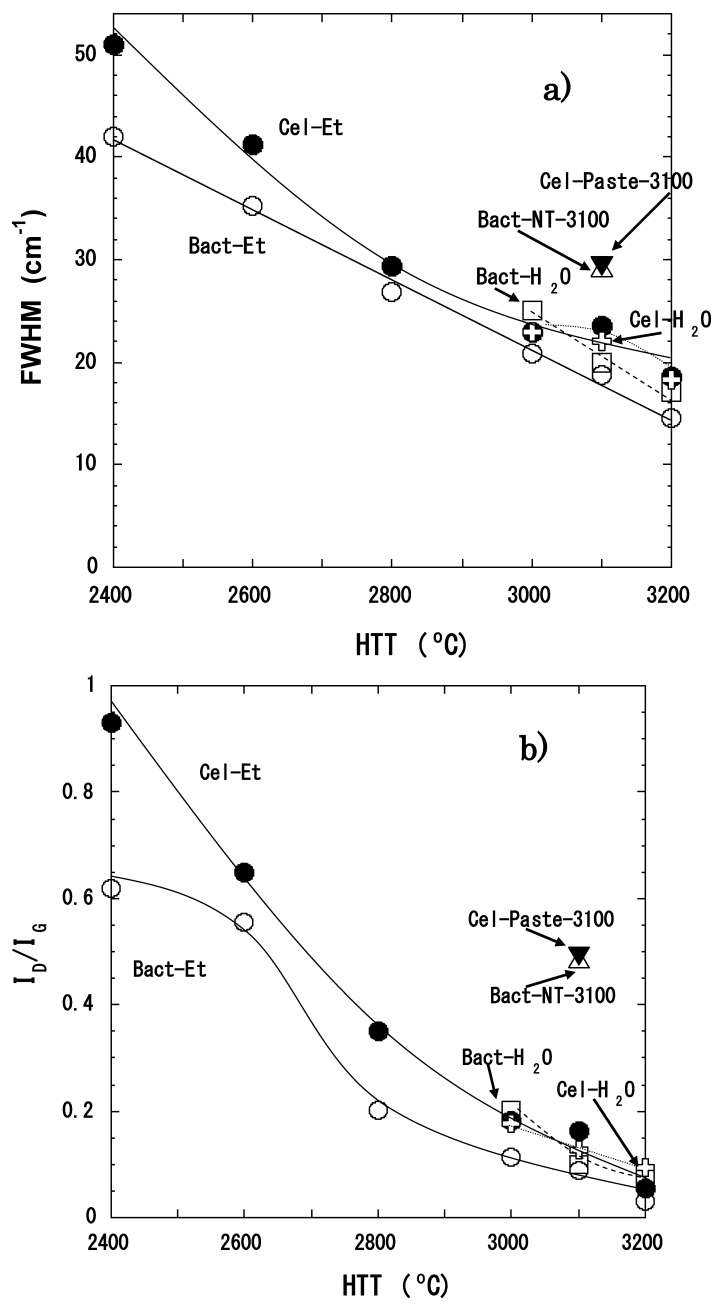

Fig. 4 FWHM of G-band G-FWHM (a) and intensity ratio $I_{\mathrm{D}} / I_{\mathrm{G}}$ (b) as a function of HTT for heat-treated samples of Cel-Et and Cel- $\mathrm{H}_{2} \mathrm{O}$ and for Cel-Paste-3100. The values of $I_{\mathrm{D}} / I_{\mathrm{G}}$ and GFWHM for the heat-treated Bact-Et and Bact- $\mathrm{H}_{2} \mathrm{O}$ and for Bact-Paste-3100 are also plotted as a function of HTT in the figures for comparison ${ }^{8)}$. for Cel-Paste-3100 are larger than those for Cel- $\mathrm{H}_{2} \mathrm{O}-3100$ and CelEt-3100. For examples, the values of G-FWHM and $I_{\mathrm{D}} / I_{\mathrm{G}}$ for CelEt-3100 were 23.5 and 0.163, respectively, and those values for CelPaste-3100 were 29.4 and 0.493, respectively. The G-FWHM and $I_{\mathrm{D}} / I_{\mathrm{G}}$ values for Cel-Et-3100 roughly correspond to the $d_{002}$ value of $0.3414 \mathrm{~nm}$ and those for Cel-Paste-3100 correspond to $d_{002}=0.3418$ $0.3420 \mathrm{~nm}$ using the relations between $d_{002}$ and G-FWHM and between $d_{002}$ and $I_{\mathrm{D}} / I_{\mathrm{G}}$ for Kapton-derived carbon films ${ }^{13)}$, i.e., the structure for both Cel-Et-3100 and Cel-Paste-3100 is expected to be turbostratic. We have to consider that the information of the Raman spectrum is limited to the surface of the specimen, i.e., Raman spectrum reflects the structure, texture and orientation of carbon layers at the surface as mentioned above. Therefore, the Raman result of Cel-Et-3100 indicates that the influence of the surface texture on G-FWHM and $I_{\mathrm{D}} / I_{\mathrm{G}}$ is large, and the surface structure, i.e., degree of graphitization of the sample seemed to be underestimated. The Raman result is also probably due to the multiphase graphitization of Cel-Et-3100 being composed of graphitic and turbostratic structures. In addition, the present Raman results show that the G-FWHM and $I_{\mathrm{D}} / I_{\mathrm{G}}$ values for the heat-treated Cel-Et, Cel- $\mathrm{H}_{2} \mathrm{O}$, Bact-Et and Bact$\mathrm{H}_{2} \mathrm{O}$ gave almost the same values at the same HTT above $3000{ }^{\circ} \mathrm{C}$ and also those values for Cel-Paste-3100 gave almost the same values as those for Bact-NT-3100. As will be described later, however, the results of the XRD measurements indicate that the structure development of the heat-treated Cel-Et and Cel- $\mathrm{H}_{2} \mathrm{O}$ sheets is less than that of the heat-treated sheets of bacteria cellulose nanofibers ${ }^{8}$. The present Raman results in Fig. 4 suggest again that the influence of the surface textures of the heat-treated sheets and lumps on G-FWHM and $I_{\mathrm{D}} / I_{\mathrm{G}}$ is considerably large.

\subsection{XRD}

It was reported that no correlation was obtained between characteristics of the 002 diffraction profile of a charcoal and the crystallinity of the precursor cellulose in ref. 2. On the other hand, Kim et al. measured XRD patterns for Cladophora (algal cellulose), Halocynthia (tunicate cellulose, i.e. animal cellulose), Acetobacter (bacteria cellulose) and ramie fiber (China grass), and obtained a good correlation between the mean crystallite size of the initial cellulose nanofibrils and that of the resultant carbons heat-treated at $2000{ }^{\circ} \mathrm{C}^{5)}$. The order of the mean crystallite sizes of the cellulose nanofibrils were algal cellulose $>$ animal cellulose $>$ bacteria cellulose $>$ ramie fiber. In the present study, we measured the XRD diffraction profiles of Cel-Et (from plant pulp), Bact-Et (from bacteria cellulose) and Ani-Et (from animal cellulose), and the profiles are shown in Fig. 5. The order of crystallinity was obtained to be Ani-Et $>$ Bact-Et $>$ Cel-Et and the result is consistent with that in ref. 5. The structural improvement of carbon nanofibers derived from cellulose nanofibrils with heat treatment probably progress more remarkably for the precursor nanofibrils with better crystallinity as pointed out in ref. 5 . The less crystallinity 


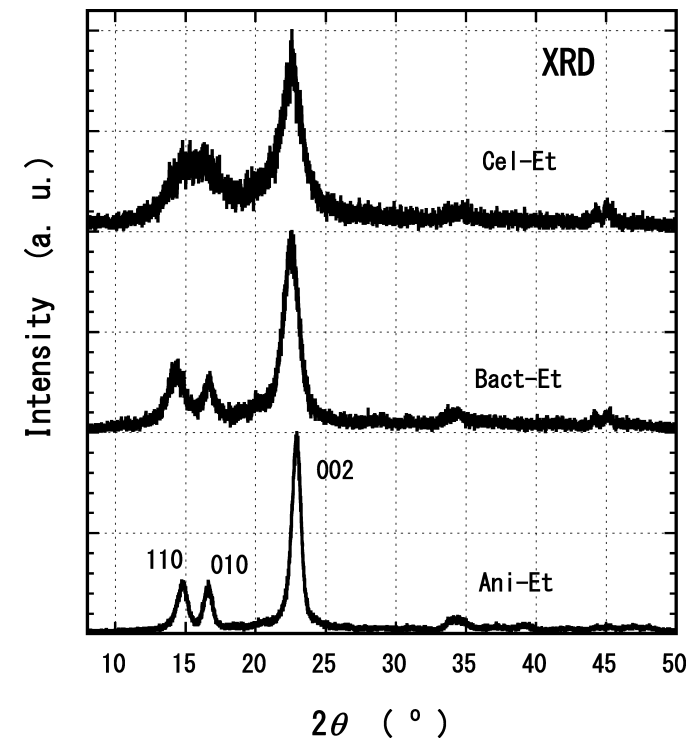

Fig. 5 XRD profiles of present Cel-Et (cellulose nanofibrils), BactEt (bacteria cellulose) and Ani-Et (animal cellulose).

of Cel-Et prepared from the commercially available cellulose paste is attributed to a plant pulp used and also to the production method i.e., smashing the plant pulp to submicroscopic fragments mechanically ${ }^{11)}$.

Fig. 6 shows the XRD profiles for the heat-treated samples. Separated 100 and 101 peaks were observed for all heat-treated Cel-Et and $\mathrm{Cel}-\mathrm{H}_{2} \mathrm{O}$ sheets as shown in Fig. 6(a). On the other hand, only 10, 002 and 004 peaks were observed for Cel-Paste-3100, exhibiting typical turbostratic structure, which is consistent with the Raman results. The turbostratic 10 peak was also observed for the heattreated sheets, but was very weak for the Cel-Et sheets heat-treated at temperatures above $2600{ }^{\circ} \mathrm{C}$. A 112 peak, reflecting the stacking regularity of carbon layers in graphite, was observed for the Cel-Et sheets heat-treated at temperatures above $2600{ }^{\circ} \mathrm{C}$ and $\mathrm{Cel}-\mathrm{H}_{2} \mathrm{O}-3000$, -3100 and -3200 . The XRD results demonstrate that a relatively large region of the Cel-Et sheet and some region of the $\mathrm{Cel}-\mathrm{H}_{2} \mathrm{O}$ sheet are graphitized by heat treatment at high temperatures. These results are consistent with the results of the TEM observations and Raman spectra measurements.

The 102 peak was observed for the heat-treated Cel-Et and Cel$\mathrm{H}_{2} \mathrm{O}$ sheets. The 102 peak was also observed for the heat-treated sheets of bacteria cellulose nanofibers and should be attributed to some arrangement and orientation of the nanofibers against each sheet plane ${ }^{8)}$. The values of the peak intensity ratio of 004 against 100 or 101, or against 102, for the heat-treated Cel-Et and Cel- $\mathrm{H}_{2} \mathrm{O}$ sheets were incoherent to HTT and scattered, as the same as those for the heat-treated sheets derived from bacteria cellulose nanofibers ${ }^{8)}$, and the incoherent values of the peak intensity ratios are probably due to the different orientation conditions of the nanofibers against sheet planes.

Asymmetrical 002 and 004 peaks were observed for the heat-treat-
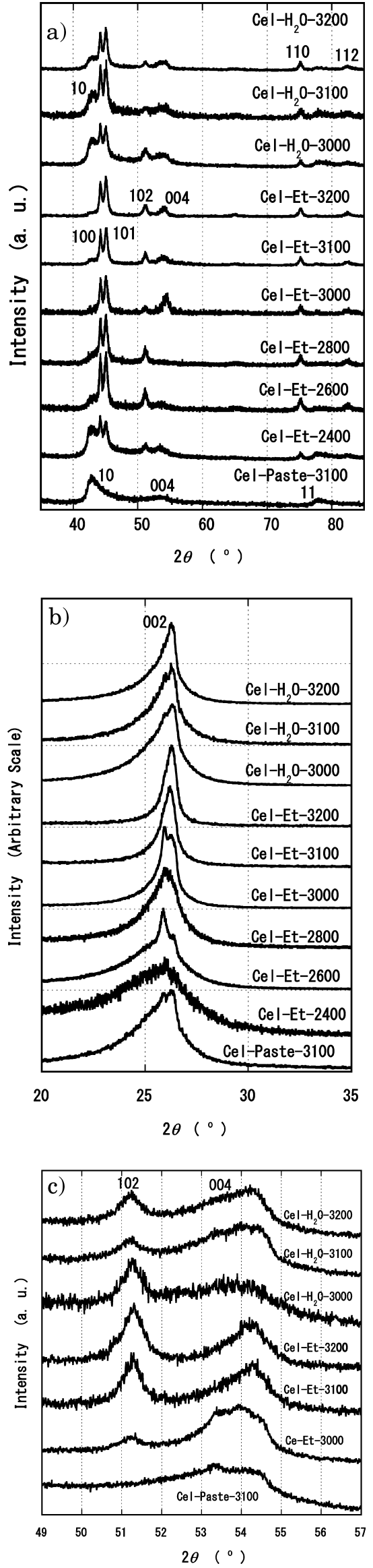

Fig. 6 XRD profiles of 100-112(a), 002(b) and 004(c) for heattreated samples of Cel-Et and $\mathrm{Cel}-\mathrm{H}_{2} \mathrm{O}$ and for CelPaste-3100. 
ed Cel-Et and $\mathrm{Cel}-\mathrm{H}_{2} \mathrm{O}$ sheets except Cel-Et-3200 as shown in Figs. 6(b) and (c), and some heat-treated sheets exhibited complex 002 and 004 peaks, which are different from the symmetrical 002 and 004 peaks for the heat-treated sheets of bacteria cellulose nanofibers ${ }^{8}$. These results indicate multiphase graphitization of the heat-treated Cel-Et and Cel- $\mathrm{H}_{2} \mathrm{O}$ sheets as observed generally for nongraphitizing carbons $^{1), 2)}$. However, the 002 diffraction profiles are also different from those for charcoals after heat-treated at high temperatures, even from those for the samples derived from crystalline cellulose components of wood, which exhibited clear double 002 peaks $^{2}$. The present XRD data indicated that the structure development of the heat-treated Cel-Et and Cel- $\mathrm{H}_{2} \mathrm{O}$ sheets is less than that of the heat-treated sheets of bacteria cellulose nanofibers ${ }^{8)}$, but better than the charcoals heattreated at high temperatures ${ }^{2)}$, i.e., the graphitized components in the heat-treated Cel-Et and Cel- $\mathrm{H}_{2} \mathrm{O}$ sheets seem to occupy smaller regions than those in the heat-treated sheets derived from bacteria cellulose nanofibers, but larger regions than those in the heat-treated charcoals. The difference in improvement of graphitization should be due to the difference in the effect of the surface graphitization. The diameters of the nanofibrils in Cel-Et and Cel- $\mathrm{H}_{2} \mathrm{O}$ were about $30-300 \mathrm{~nm}$ with a broad distribution of their diameters, while the diameters of the bacteria cellulose nanofibers were $30-60 \mathrm{~nm}^{7), 8}$, and the sizes of the charcoal particles should be micrometric because the XRD measurements were made according to so-called Gakushin $\operatorname{method}^{14)}$.

The values of $d_{002}$ for the heat-treated sheets and Cel-Paste-3100 are plotted as a function of HTT in Fig. 7. The values of $d_{002}$ for the heat-treated Bact-Et and Bact- $\mathrm{H}_{2} \mathrm{O}$ and for Bact-NT-3100 are also plotted as a function of HTT for comparison ${ }^{8}$. Because of the asymmetrical or complex 002 peaks for the present heat-treated sheets,

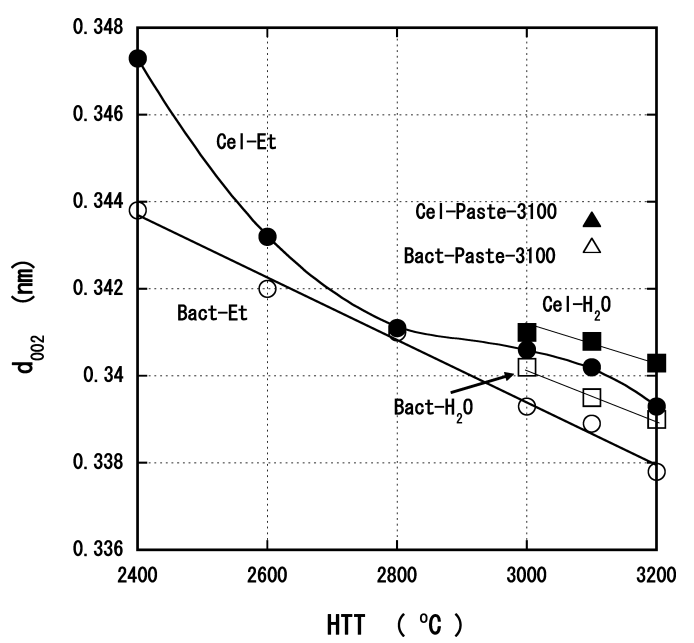

Fig. $7 d_{002}$ plotted as a function of HTT for heat-treated sheets of Cel-Et and Cel- $\mathrm{H}_{2} \mathrm{O}$ and for Cel-Paste-3100. The values of $d_{002}$ for the heat-treated Bact-Et and Bact- $\mathrm{H}_{2} \mathrm{O}$ sheets and for Bact-Paste-3100 are also plotted as a function of HTT for comparison $^{8)}$. the $L_{\mathrm{c}}$ values were not evaluated and the $d_{002}$ values obtained are the mean values for turbostratic and graphitic components in each sample. $d_{002}$ decreases with increasing HTT for both of the heat-treated Cel-Et and Cel- $\mathrm{H}_{2} \mathrm{O}$ sheets. The tendency of the HTT dependence of $d_{002}$ shown in Fig. 7 is similar to those of G-FWHM and $I_{\mathrm{D}} / I_{\mathrm{G}}$ shown in Fig. 4, except some respects due to the influence of surface texture on G-FWHM and $I_{\mathrm{D}} / I_{\mathrm{G}}$. The $d_{002}$ values for Cel-Et-3100 and CelPaste-3100 are 0.3402 and $0.3436 \mathrm{~nm}$, respectively, while from the G-FWHM and $I_{\mathrm{D}} / I_{\mathrm{G}}$ data for Cel-Et-3100 and Cel-Paste-3100 the $d_{002}$ values were estimated to be $0.3414 \mathrm{~nm}$ and $0.3418-0.3420 \mathrm{~nm}$ as described in Section 3.3 ${ }^{13)}$. The difference in the $d_{002}$ values for CelEt-3100 and Cel-Paste-3100 between the measured values and those estimated from the Raman data are probably due to following reason. Cel-Paste-3100 has a lump shape and the surface is rather smooth, so that the Raman spectrum reflects the improvement of structure on the surface mainly, while Cel-Et-3100 has a rough surface texture as shown in Fig. 1(g), so that the texture and orientation of carbon layers at the surface affect the Raman spectrum considerably.

At the same HTT above $3000{ }^{\circ} \mathrm{C}$, the $d_{002}$ value for the heattreated Cel-Et sheet is smaller than that for the heat-treated Cel- $\mathrm{H}_{2} \mathrm{O}$ sheet and much smaller than that for Cel-Paste-3100, i.e., the order of the degree of graphitizability is Cel-Et $>\mathrm{Cel}-\mathrm{H}_{2} \mathrm{O}>\mathrm{Cel}-\mathrm{Paste}$, and the order is the same as that of the carbon nanofibers derived from bacteria cellulose, Bact-Et $>$ Bact- $\mathrm{H}_{2} \mathrm{O}>$ Bact- $\mathrm{NT}^{8}$. . However, the $d_{002}$ values for the heat-treated $\mathrm{Cel}-\mathrm{Et}$ and $\mathrm{Cel}-\mathrm{H}_{2} \mathrm{O}$ sheets and CelPaste-3100 are larger than those for the heat-treated Bact-Et and Bact- $\mathrm{H}_{2} \mathrm{O}$ sheets and Bact-NT-3100, respectively. The structural improvement of carbon nanofibers derived from cellulose nanofibrils with heat treatment should progress more remarkably for thinner diameter, better separation and better crystallinity of the nanofibrils, and also narrower distribution of their diameters.

\subsection{Electric resistivity}

The $\rho$ values for Cel-Et-3000, -3100 and -3200 are listed in Table 1. The $\rho$ values for Bact-Et-3000, -3100 and -3200 are also listed in the table for comparison ${ }^{8)}$. The values for the Cel-Et samples are larger than those for the Bact-Et samples, but not so much different from those values. The results are in consistent with those of the XRD measurements. These $\rho$ values also larger than the volume resistivity of a commercially available powder of vapor grown carbon

Table 1 Values of sheet resistivity $\rho$ for Cel-Et-3000, -3100 and -3200 . Values of the sheet $\rho$ resistivity for Bact-Et-3000, -3100 and -3200 are also listed in the table for compari$\operatorname{son}^{8)}$.

\begin{tabular}{lccc}
\hline \multirow{2}{*}{$\rho$ of sample } & \multicolumn{3}{c}{$\mathrm{HTT}$} \\
\cline { 2 - 4 } & $3000{ }^{\circ} \mathrm{C}$ & $3100{ }^{\circ} \mathrm{C}$ & $3200{ }^{\circ} \mathrm{C}$ \\
\hline $\operatorname{Cel}-\operatorname{Et}(\Omega \mathrm{m})$ & $3.53 \times 10^{-4}$ & $3.32 \times 10^{-4}$ & $2.84 \times 10^{-4}$ \\
$\operatorname{Bact}-\operatorname{Et}(\Omega \mathrm{m})$ & $2.71 \times 10^{-4}$ & $1.80 \times 10^{-4}$ & $1.34 \times 10^{-4}$ \\
\hline
\end{tabular}


fibers heat-treated at high temperature, $\operatorname{VGCF}^{\circledR},\left(1.2 \times 10^{-4} \Omega \cdot \mathrm{m}\right)$. If the good separation of each carbon nanofiber after heat-treated at high temperature is achieved, for example the cellulose nanofibrils prepared by freeze dry in an organic solvent, there is a possibility as electrical conductive additives for CFRP with high performance.

\section{Summary}

Structural order of carbon nanofibers improves with increasing HTT in the carbon sheets derived from cellulose nanofibrils of plant origin dispersed in ethanol or distilled water, especially those dispersed in ethanol, though a turbostratic component was also observed even for the sheet heat-treated at $3200{ }^{\circ} \mathrm{C}$. On the other hand, a bulk carbon derived from the original cellulose nanofibril paste exhibited a typical turbostratic structure even after heat-treated at $3100{ }^{\circ} \mathrm{C}$. The development of graphite structure in the carbon sheets is probably attributed to the surface graphitization, i.e., a graphitization behavior on the surfaces of the carbon nanofibers and also on their insides because of the thin diameters of about $30-300 \mathrm{~nm}$, as the same as the graphitization of the carbonized sheets prepared from the bacteria cellulose nanofibers with $30-60 \mathrm{~nm}$ in diameter dispersed in ethanol or distilled water by simple heat treatment at high temperatures ${ }^{7), 8}$. The structure development of the heat-treated Cel-Et and $\mathrm{Cel}-\mathrm{H}_{2} \mathrm{O}$ sheets is less than that of the heat-treated sheets of bacteria cellulose nanofibers ${ }^{8)}$. The structural improvement of carbon nanofibers derived from cellulose nanofibrils with heat treatment should progress more remarkably for thinner diameter, better separation and better crystallinity of the nanofibrils, and also narrower distribution of their diameters.

\section{Acknowledgment}

One of the authors Y. K. acknowledges the financial support by a
Grant-in-Aid for Science Research No. 23560806 from the Japan Society for the Promotion of Science (JSPS)

\section{References}

1) M. Inagaki and F. Kang, Carbon materials science and engineering, From fundamentals to applications (2006) pp. 391-413, Beijing, Tsinghua University Press.

2) S. Otani and A. Oya, TANSO 1971 [No.64] 10-13 [in Japanese].

3) Y. Hishiyama, A. Yoshida and Y. Kaburagi, Carbon 31 (1993) 12651272.

4) Y. Kaburagi, K. Hoshoya, A. Yoshida and Y. Hishiyama, Carbon 43 (2005) 2817-2819.

5) D. Y. Kim, Y. Nishiyama, M. Wada and S. Kuga, Carbon 39 (2001) 1051-1056.

6) C. H. Haigler, A. R. White, R. M. Brown Jr. and K. M. Cooper, J. Cell Biol. 94 (1982) 64-69.

7) Y. Kaburagi, M. Ohoyama, Y. Yamaguchi, E. Shindou, A. Yoshida, N. Iwashita, N. Yoshizawa and M. Kodama, Carbon 50 (2012) 4757-4760.

8) Y. Kaburagi, M. Ohoyama, Y. Yamaguchi, E. Shindou, A. Yoshida, N. Iwashita, N. Yoshizawa and M. Kodama, TANSO 2012 [No.255] 225230.

9) N. Yoshizawa, M. Kodama and G. Sugino, Extended abstracts, 2nd Nano Today Conference (USA) (2011) P6-22(CD-R), Elsevier.

10) N. Yoshizawa, M. Kodama, K. Kawasaki and G. Sugino, Carbon2012 (2012) Extended Abstracts (CD-ROM), ID556, Krakow, Poland.

11) Daicel Fine Chem Ltd., http://daicelfinechem.jp/business/wspdiv/celish. html

12) Y. Kaburagi, A. Yoshida, K. Hosoya, E. Shindou and Y. Hishiyama, International Symposium on Nanocarbons, Hotel Metropolitan (Nagano, Japan), JSPS (2004) p. 90.

13) A. Yoshida, Y. Kaburagi and Y. Hishiyama, Carbon 44 (2006) $2333-$ 2335 .

14) N. Iwashita, C. R. Park, H. Fujimoto, M. Shiraishi and M. Inagaki, Carbon 42 (2004) 701-714. 